\title{
THE EFFECTIVENESS OF ADSORBENT DERIVED FROM MORINGA OLEIFERA AS A WATER TREATMENT AGENT
}

\author{
FARASYAHIDA A. SAMAD ${ }^{A}$, WAN SALIDA WAN MANSOR ${ }^{B}$ AND HIDAYATUL AINI \\ ZAKARIA \\ ${ }^{a, b, c}$ Faculty of Ocean Engineering Technology and Informatics, Universiti Malaysia Terengganu, 21030 Kuala Nerus, \\ Terengganu, Malaysia \\ *Corresponding author: hidayatul@umt.edu.my
}

\begin{abstract}
Clean, safe and readily available water is very crucial in everyday life, especially for health, hygiene, and the productivity of the community. Unfortunately, increase in contaminants in water supplies from human activities and industrialization is very worrying. Conventional wastewater treatment includes the usage of alum that will affect health with prolonged consumption. This research was carried out to focus on the development of wastewater treatment system using adsorbent from Moringa oleifera seeds. Adsorbent was successfully synthesized from the seeds of Moringa oleifera. Characterization of the sample was made using X-Ray Diffraction (XRD), Fourier Transform Infrared Spectroscopy (FTIR), Scanning Electron Microscope (SEM), while the effectiveness of water treatment was analyzed using Turbidity Meter. Then, all samples were tested against kaolin wastewater. XRD results showed that all the adsorbent samples were amorphous in nature. FTIR results indicated that there were hydroxyl group and carboxylic group in the sample representing numerous oxygen-riddled functional groups on the surface. From SEM results, it was clearly shown that the pore structure and size of Moringa oleifera affected the capability of adsorption where the smaller the size, the more effective the sample. Turbidity test showed that the sample that worked best for wastewater treatment was adsorbent from Moringa oleifera seeds in size of $125 \mu \mathrm{m}$ that was heated for 4 hours with $93.76 \%$ turbidity removal. Therefore, this study proved that the adsorbent from Moringa oleifera seeds is very suitable for high turbidity wastewater treatment. Further studies investigating the combination of conventional activated carbon with adsorbent from Moringa oleifera seeds should be conducted before these samples are made available for further use so that we can compare which sample works best for wastewater treatment.
\end{abstract}

Keywords: Water pollution, water treatment, wastewater, activated carbon, moringa oleifera

\section{Introduction}

\section{Background of the Study}

Water is a fundamental need for almost every living organism to sustain their living mechanism. However, pure water has become vastly depleted due to the water contamination resulting from heavy duty industrial boom over the years (Zhou and Smith, 2002). Water pollution is a huge problem for the entire world leading to bad surrounding atmosphere and human health. According to UNICEF, 783 million people worldwide in undeveloped countries are living without access to clean water, and the World Health Organization estimates that lack of proper drinking water causes 1.6 million deaths from diarrheal and parasitic diseases each year (Phyu and Kyu, 2017).
Polluted water is not only filthy, it may cause hazardous health effect if consumed. Every year about 1.8 million people die due to diarrheal diseases (Eman et al., 2010). Polluted water has caused many ailments worldwide easily preventable by easy and continuous access to clean water. The United Nations has indicated that basic human right includes general access to clean water which is fundamental towards cultivating living standards worldwide. In most cases, water-poor communities are economically deprived as well, and these communities live in ongoing cycles of poverty through many generations. The water wells, rivers or ponds are the main sources for daily use especially in underdeveloped countries. Alternative methods for wastewater treatment should be taken by these communities when natural disasters occur 
that lead to sources of clean water being cut off while waiting for clean water supplies to arrive. An example of water treatment used in underdeveloped countries is filtration of water through aquifer sediments and soil. This makes it safe to drink the groundwater supply.

Currently, the most fundamental need of the countries is to be able to provide clean drinking water using cost effective means, especially the underdeveloped countries where clean drinking water is a precious commodity. Dr. Tedros Adhanom Ghebreyesus, the DirectorGeneral of WHO, said, "Safe water, sanitation and hygiene at home should not be a privilege of only those who are rich or live in urban centres. These are some of the most basic requirements for human health, and all countries have a responsibility to ensure that everyone can access them." Aluminum is one of the atypical chemical coagulants widely used for turbidity removal in water and wastewater treatment, but it may pose several health problems (Saharudin, 2014). Therefore, natural coagulants or biocoagulant offer a better alternative compared to chemical coagulants in terms of health risksbenefits, cost-effectiveness and environmental sustainability. Coagulants from natural, biodegradable resources like plants, animals and microorganisms have creatd the interest in finding replacement for alum so as to prevent utmost dependency on alum usage (Kaggwa et al., 2001).

In regards to solving this problem, the idea of this research is to develop the water treatment process using adsorbent from Moringa oleifera seeds. Adsorbent may comprise a carbonaceous, highly porous adsorptive medium that has a complex structure composed primarily of carbon atoms. The grids of pores in activated carbons are tunnels created within a rigid frame of disordered layers of carbon atoms, linked together by chemical bonds, stacked disproportionately, creating a highly porous structure of nooks, crannies, cracks and crevices between the carbon layers (Bina et al., 2010).
Adsorption is a natural way to make the drinking water safe for consumption, by filtering out the chemicals used in the sanitation process of purifying water or other contaminants in the well water. Adsorption filters will also get rid of the turbidity, bad taste and odour of the water, making it more hygiene (Muyibi, Evison, 1996). On other hand, granular or powdered activated carbon which is a type of adsorbent, is commonly used in developed countries for community water treatment where normally it is used for instant household water treatment. Past research has shown that activated carbon was able to treat water on its own.

\section{Problem Statement}

Water is the most abundant substance on the planet, where it covers more than $70 \%$ of the earth surface. Human beings are also the same where we are largely made up of water, and we require it in order to survive (Gholamreza et al., 2009). The effect of water pollution is usually staggering, and when humans are unable to get access to fresh, clean water for long periods of time, the chances of disease and even death increase dramatically at a much higher rate (Jadhav, Mahajan, 2013).

The main objective of coagulation in wastewater treatment is to remove impurities and turbidity from the water, where coagulation is one of the most conventional practices for large scale water desalination. Aluminium and iron coagulants are commonly used in most industries (Forster, 2000). However, when these two elements are used as coagulants in wastewater treatment, they may cause several dire effects on human health, including intestinal constipation, loss of memory, convulsions, abdominal colic, loss of energy and learning difficulties (Choy et al., 2003).

Hence, nowadays, there has been great attention given to the improvement and implementation of natural coagulants in wastewater treatment (Monica, Chris, 2016). Natural coagulant chosen for this research was adsorbent derived from the seeds of Moringa 
oleifera. It was shown in previous studies that seeds of Moringa oleifera were one of the most effective primary coagulants for water treatment. The advantage of this plant over the chemical treatments is that it is biological and edible (Mokhtar et al., 2013). Past studies have shown the efficiency of Moringa oleifera as adsorbent in wastewater treatment system (Delelegn, Sahile, \& Husen, 2018)and deaths among children are caused by germs, which get into the mouth via water and food. In addition, it has been estimated that up to $80 \%$ of all disease and sickness in the world is caused by inadequate sanitation, polluted water or unavailability of water. Thus, this study investigates the water purifying property of Moringa oleifera seed powder and determines the role of seed extracts against a few bacterial growths.", "author" : [ \{ "dropping-particle" : “", "family" : "Delelegn", "given" : "Ashenafi", "non-dropping-particle" : “", "parse-names" : false, "suffix" : “" \}, \{ "dropping-particle" : "", "family" : "Sahile", "given" : "Samuel", "non-dropping-particle" : “", "parse-names" : false, "suffix" : “" $\},\{$ “dropping-particle” : “", "family" : "Husen”, "given" : "Azamal”, "nondropping-particle” : “”, "parse-names” : false, "suffix": "” \} ], "container-title" : "Agriculture \& Food Security", "id" : "ITEM-1", "issue" : "1", “issued" : \{ "date-parts" : [ [ "2018”, “3” ] ] \}, "page" : "25", "title" : "Water purification and antibacterial efficacy of Moringa oleifera Lam", "type" : "article-journal", "volume" : "7" \}, "uris" : [ "http://www.mendeley.com/ documents/?uuid=8ee216be-d430-47278977-ae76a43325c6" ] \} ], "mendeley" : \{ "formattedCitation" : "(Delelegn, Sahile, \& Husen, 2018, (Choudhary \& Neogi, 2017)(Shan, Matar, Makky, \& Ali, 2017); however, currently there are no studies conducted on the effect of combining conventional activated carbon derived from coconut shells and adsorbent derived from Moringa oleifera. Hence, the main objective of this study is to evaluate the effectiveness of the combination of these two widely known wastewater treatment agents.

\section{Research Objectives}

With regards to the study, there are objectives:

1. To synthesize adsorbent from the seeds of Moringa oleifera (MO)

2. To study the sample characteristics using XRD, FTIR, and SEM

3. To study the effectiveness of adsorbent derived from Moringa oleifera seeds as a wastewater treatment agent.

\section{Scope of Study}

This research focused on the preparation of adsorbent from Moringa oleifera seeds. The adsorbent was prepared in the form of powder. There were 9 samples altogether where the sizes and heating time were different. From there, the samples underwent turbidity test using turbidity meter to determine which sample was the most effective for water treatment. Hence, all the samples were characterized using XRD, FTIR, and SEM. Data analysis was done to prove which sample worked best in this research.

\section{Significance of Study}

Moringa oleifera poses an exciting alternative to replace potentially harmful synthetic coagulants to reduce the turbidity of the water and make it more suitable and safer to be consumed by humans (Adeniran et al., 2017). It is widely accepted in the scientific community that wastewater treatments with Moringa oleifera solutions will remove $90 \%-99.9 \%$ of the impurities in water (Warhust et al., 1996).

\section{Materials and Methods}

\section{Sample Preparation:}

\section{Moringa Oleifera}

Moringa oleifera seeds were sun dried for 24 hours to remove any inorganic impurities and crusts. The seeds were then further dried in the oven at $80^{\circ} \mathrm{C}$ for 24 hours. The seeds were grinded and sieved to different sizes which were $125 \mu \mathrm{m}, 180 \mu \mathrm{m}$ and $250 \mu \mathrm{m}$ (Abidin et al., 2014). 


\section{Adsorbent}

All the samples in different sizes were mixed with $\mathrm{H}_{2} \mathrm{PO}_{4}$ solution in concentration of $0.1 \mathrm{M}$. Then the water was dried at $130^{\circ}$ for 24 hours in a sealed oven. Next, the samples were heated from room temperature to $400^{\circ}$ in different periods for 1, 2 and 4 hours. The samples then were rinsed using $\mathrm{H}_{2} \mathrm{PO}_{4}$ and dried at $105^{\circ}$ for 1 hour (Mokhtar et al., 2013).

\section{Preparation of Kaolin Wastewater}

$10 \mathrm{~g}$ of dry kaolin was dispersed into 1 litre of distilled water then mixed and stirred using magnetic stirrer for 1 hour. The prepared kaolin wastewater suspensions were allowed to settle for 24 hours to allow complete hydration of the kaolin. The kaolin suspension was used as the stock solution for the preparation of water samples of varying turbidities for the tests (Saharudin, Rajesh, 2014).

\section{Sample characterization}

\section{$X$-Ray Diffraction (XRD)}

Figure 1 shows XRD machine which is a rapid analytical technique primarily used for phase identification of a crystalline material and can provide information on unit cell dimensions. Rigaku MiniFlex II X-ray Diffractometer was used to determine the identification of crystalline phases of the activated carbon from the Moringa oleifera seeds and the quantitative phase analysis. The samples were put onto a glass slide, then it was placed on the holder and scanned in between $0^{\circ}$ to $80^{\circ}$. Then, XRD graphs of each sample were plotted corresponding to their diffraction peaks.

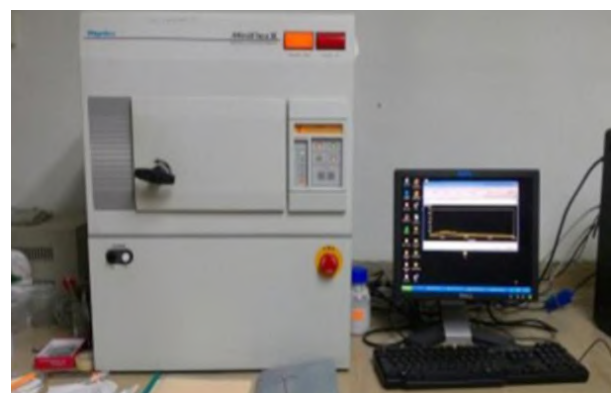

Figure 1: XRD

\section{Fourier Transform Infrared (FTIR)}

Figure 2 shows the Fourier Transform Infrared, IRTracer-100 FTIR Spectrophotometer that was used to identify the presence of certain functional groups in the sample. The unique collection of absorption bands may also serve as spectral fingerprint or identification to confirm the distinctiveness of a pure compound or to detect the presence of specific impurities. The usefulness of infrared spectroscopy arises to determine different chemical structures of the samples produced. The wavelength was fixed from 400 to $4000 \mathrm{~cm}^{-1}$ and was set to transmitter mode. Then, the graphs of FTIR spectrum were plotted to determine each functional group that appeared on the surface of the samples.

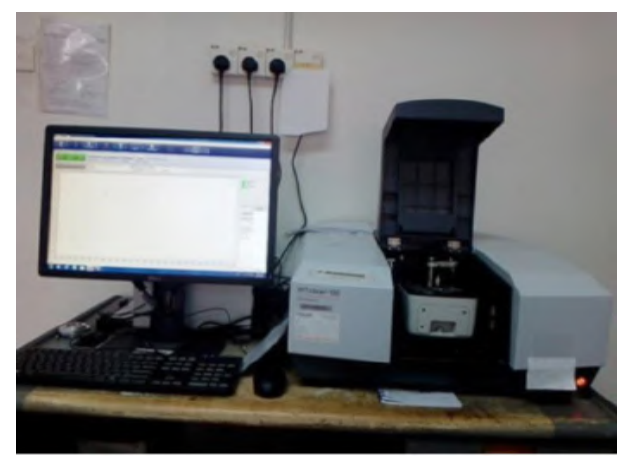

Figure 2: FTIR machine

\section{Scanning Electronic Microscope (SEM)}

Figure 3 shows the scanning electron microscope (SEM) that uses a focused beam of high-energy electrons to generate a variety of signals at the surface of solid specimens. The signals that derive from electron-sample interactions reveal information about the sample including external morphology (texture), chemical composition, and crystalline structure and orientation of materials making up the sample. In most applications, data were collected over a selected area of the surface of the sample, and a 2-dimensional image was generated which displayed spatial variations in these properties. 


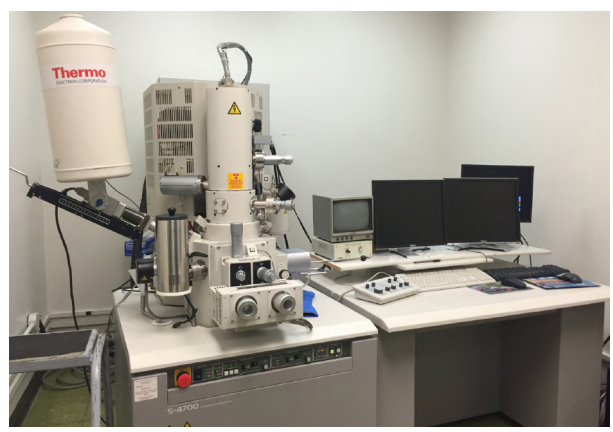

Figure 3: SEM

\section{Turbidity Meter}

Figure 4 shows Thermo Orion AQ3010 Turbidity Meter. Turbidity can be measured using either an electronic turbidity meter or a turbidity tube. Turbidity is measured in nephelometric turbidity units (NTU). Turbidity meter uses nephelometry (90 degree scattering) or other optical scatter detection techniques for rapid, scientifically accurate turbidity measurements on water samples. All the samples underwent turbidity test where the NTU readings of kaolin wastewater were taken first and then $1.0 \mathrm{~g}$ of AC from MO seeds was added in the water sample. After that, the NTU readings of the mixture were taken in 30 minutes time for every 2 minutes time interval.

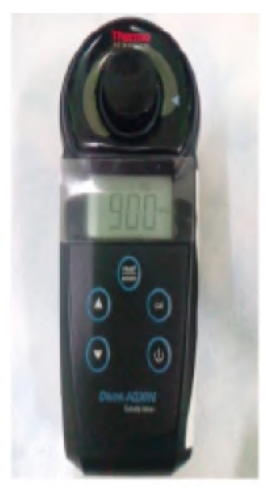

Figure 4: Turbidity meter

\section{Results and Discussion}

\section{X-Ray Diffraction}

Figure 5 shows XRD spectrum of adsorbent from Moringa oleifera seeds. From all 9 samples that had been analysed, this is the average spectrum formed. The diffraction peak at the position of $25^{\circ}$ corresponding to 001 showed that the samples were amorphous in nature similar to conventional AC. Studies of XRD analysis stated that even if the sample did not show certain characteristics such as crystal angles related to crystalline state, the potential of molecular structure of crystalline still existed (Amagloh, Amos, 2009).

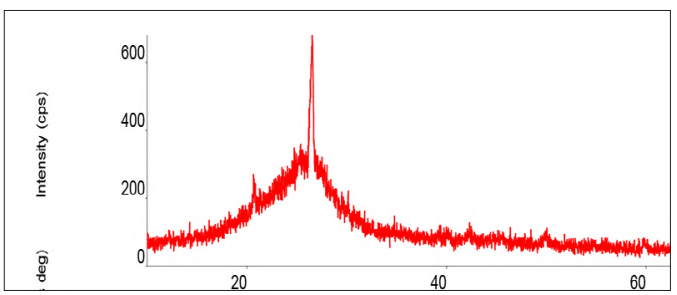

Figure 5: XRD graph of adsorbent from Moringa oleifera seeds

\section{FTIR}

Figure 6 shows one of the FTIR spectrums of AC from Moringa oleifera seeds where all of the samples had quite similar spectrum. The absorption peak at $3300.2 \mathrm{~cm}^{-1}$ indicated $\mathrm{N}-\mathrm{H}$ stretch unsubstituted two bonds of Amide group while peak $1641.42 \mathrm{~cm}^{-1}$ showed the $\mathrm{C}=\mathrm{O}$ stretch of Amide group. Peak 1535.34 $\mathrm{cm}^{-1}$ referred to $\mathrm{C}=\mathrm{C}$ stretch of alkenes of the aromatic ring with medium-weak and multiple bands whereas peak $1431.18 \mathrm{~cm}^{-1}$ showed $-\mathrm{C}-\mathrm{H}$ bending of alkane group. Peak at $1037.7 \mathrm{~cm}^{-1}$ indicated coupling mode of $\mathrm{C}-\mathrm{O}$ stretch and ester stretch vibrations with two bands or more while $1242.16 \mathrm{~cm}^{-1}$ represented $\mathrm{C}-\mathrm{N}$ stretch of Amine group (Adeniran et al., 2017). 


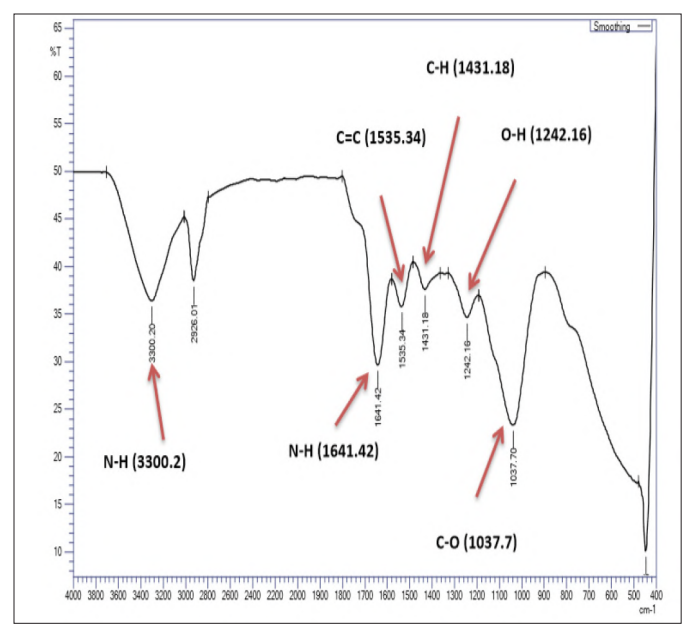

Wavenumber $\left(\mathrm{cm}^{-1}\right)$

Figure 6: FTIR spectrum of adsorbent from Moringa oleifera

\section{SEM}

Figure 7 shows the pore structure of adsorbent from Moringa oleifera in size of $125 \mu \mathrm{m}$ and heated for 4 hours. The average size of the pore of this sample was $1.16 \mu \mathrm{m}$ which was the finest compared to the others. Hence, this sample showed the highest percentage of turbidity removal which was $93.76 \%$ as shown in Table 4.3. This is because the turbid and dirt could pass through the small pore size so it had the biggest rate of adsorption. This explains why the sample gave the least final NTU reading on turbidity meter as in Table 1.

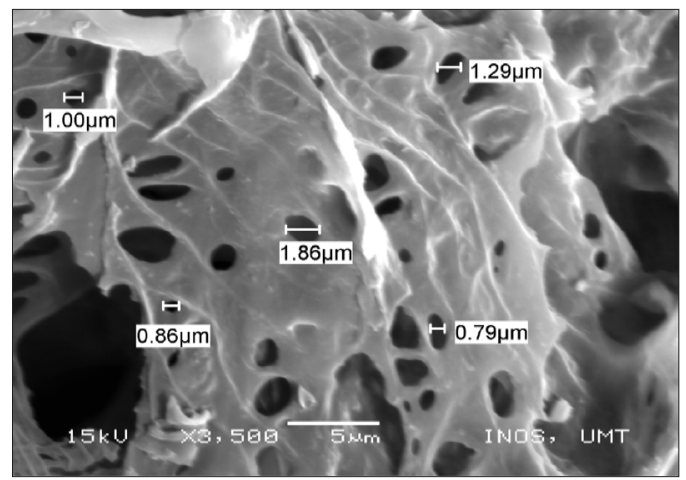

Figure 7: Pore size of adsorbent from Moringa oleifera

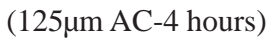

From this research, it was proven that adsorbent from Moringa oleifera had been processed to produce porous structure and large surface area suitable for adsorption. Thus, Moringa oleifera became the most effective natural agent for water treatment due to its complex pore structure, large specific surface area, and various functional groups on the surface (Mokhtar, 2013).

\section{Turbidity Meter}

Table 1 shows the percentage of turbidity removal for all the samples. The percentage of turbidity removal for sample (II) was $93.76 \%$ which was the highest. The second sample that had higher percentage was sample (VIII) that was $91.33 \%$. The difference between these two was the heating time. Sample (II) was heated for 4 hours while sample (VIII) was heated for 1 hour only. It shows that sample (II) was at the optimum heating time for the sample to work at its best. The efficiency of $\mathrm{AC}$ was proven in this study as Moringa oleifera is known for its purifying nature in treating water. This is due to the pore structure of AC that affects the rate of adsorption (Rohan et al., 2017). The least percentage of turbidity removal was sample (VII) which was $30.56 \%$. This is more likely because the pore size was quite big so the dirt and turbid could not pass through it, leading to small rate of adsorption. Although the sample did not reach $100 \%$ turbidity removal, it removed almost all the turbid and the outcome was comparable to the conventional AC. Thus, this study shows the efficiency of MO as a good natural agent in treating water. 
Table 1: Percentage of turbidity removal from various sample of AC

\begin{tabular}{|c|c|c|}
\hline & Sample & Percentage of Turbidity Removal (\%) \\
\hline i. & Conventional AC & 100.00 \\
\hline ii. & $0.1 \mathrm{~g}$ of $125 \mu \mathrm{m} \mathrm{AC} \mathrm{(4} \mathrm{hours)}$ & 93.76 \\
\hline iii. & $0.1 \mathrm{~g}$ of $180 \mu \mathrm{m}$ AC (4 hours) & 91.27 \\
\hline iv. & $0.1 \mathrm{~g}$ of $250 \mu \mathrm{m} \mathrm{AC}$ (4 hours) & 48.96 \\
\hline v. & $0.1 \mathrm{~g}$ of $125 \mu \mathrm{m} \mathrm{AC}$ ( 2 hours $)$ & 68.46 \\
\hline vi. & $0.1 \mathrm{~g}$ of $180 \mu \mathrm{m} \mathrm{AC}$ ( 2 hours $)$ & 63.96 \\
\hline vii. & $0.1 \mathrm{~g}$ of $250 \mu \mathrm{m} \mathrm{AC}$ ( 2 hours $)$ & 30.56 \\
\hline viii. & $0.1 \mathrm{~g}$ of $125 \mu \mathrm{m} \mathrm{AC}$ (1 hour) & 91.33 \\
\hline ix. & $0.1 \mathrm{~g}$ of $180 \mu \mathrm{m} \mathrm{AC} \mathrm{(1} \mathrm{hour)}$ & 72.61 \\
\hline $\mathrm{x}$. & $0.1 \mathrm{~g}$ of $250 \mu \mathrm{m} \mathrm{AC}$ ( 1 hour) & 50.14 \\
\hline
\end{tabular}

\section{Conclusion}

The sample used for this research was the seeds of Moringa oleifera from which its adsorbent properties was extracted. Recently, there has been increased interest in the usage of natural agents for treating water as the quality of the natural coagulants is comparable to the commercial ones. Promotion and development of Moringa oleifera as natural agents offer many diverse advantages to developing countries. According to the results of optimizing the conventional treatment, the seeds of Moringa oleifera were found to be used for simultaneous coagulation and disinfection in water treatment. The use of adsorbent is the best as it acts as catalyst in treating the wastewater. Based on the optimum results, the household water treatment can be applied practically which Moringa oleifera seeds have proven their efficiency especially in highly turbid water. This is due to their advantageous qualities which are harmless, biodegradable, non-toxic, non-corrosive, easy to use, able to remove dirt, and edible.

In conclusion, the adsorbent from the seeds of Moringa oleifera was synthesized during the preparation of the samples. All the samples were characterized for the physical and chemical composition using XRD, FTIR, and SEM whereas for the effectiveness of water treatment, the samples were characterized using turbidity meter. The $125 \mu \mathrm{m}$ adsorbent from Moringa oleifera that was heated for 4 hours showed the best results where the final NTU reading was the least which was $25.7 \mathrm{NTU}$, and the percentage of turbidity removal was the highest which was $93.76 \%$. This research showed that the sample had the complex pore structure, large specific surface area, and various oxygen-containing functional groups on the surface necessary for adsorbent properties. Differences in pore size and shape give tremendous effects on the adsorption capability of an activated carbon as the pore structure of activated carbon plays an important role (Mokhtar et al., 2013). Although the sample did not reach $100 \%$ of turbidity removal, the effectiveness was comparable to that of the conventional one.

\section{Acknowledgements}

I would like to thank all those people who made this thesis possible and it was an enjoyable experience for me to fulfill my wish to contribute positively towards this field.

First of all, I wish to express my sincere gratitude to my supervisor, Dr Hidayatul Aini Binti Zakaria that helped me a lot, taught me, and guided me along this journey, with complete patience. I also wish to thank my co-supervisor Dr Wan Salida who gave me lots of help, in particular on the methodological aspects. Without them, I would not be able to complete this research.

I am totally grateful to my friends for their encouragement and help especially to Nurul Syiffa Ishak, Raihan Ramli and Elizernithiya. They helped and assisted me in completing all the preparations for the project. Besides, they 
have shared a lot of knowledge and opinion for each and everything that should be done. I sincerely appreciate their encouragement and help along this journey.

Finally, I would like also to express my deepest gratitude for the constant support, emotional understanding, and love that I received from my family as they always acted as my supporters especially when I was facing some problems along this journey. I would not be able to complete this project if they were not by my side.

\section{References}

Abidin Z. Z., Mohamed M. F., Liew Abdullah A. G. (2014) Preliminary Study of Rambutan (Naphelium Lappaceum) Seed as Potential Biocoagulant for Turbidity Removal. Advanced Material Research. 917, 96-105.

Abidin Z. Z., Mohd Shamsudin N. S., Madehi N., \& Sobri S. (2013). Optimisation Of a Method to Extract the Active Coagulant Agent from Jatropha Curcas Seeds for Use in Turbidity Removal. Industrial Crops and Products, 41(1), 319-323.

Adeniran K. A., Akpenpuun T. D., Akinyemi B. A., \& Wasiu R. A. (2017). Effectiveness of Moringa oleifera Seed as A Coagulant in Domestic Wastewater Treatment. African Journal of Science, Technology, Innovation and Development, 9(3), 323-328.

Amagloh F. K., Amos B. (2009). Effectiveness of Moringa Oleifera Seed as Coagulant for Water Purification. African Journal of Agriculture Research, 4 (1), 119-123.

Bina B., Mehdinejad M. H., Dalhammer G., Rajarao G., Nikaen M., \& Attar H. M. (2010). Effectiveness of Moringa oleifera Coagulant Protein as Natural Coagulant aid in Removal of Turbidity and Bacteria from Turbids Waters. Engineering Technology, 4: 7-28, 67.
Choudhary, M., \& Neogi, S. (2017). A natural coagulant protein from Moringa oleifera: isolation, characterization, and potential use for water treatment. Materials Research Express, 4(10), 105502.

Choy S. Y., Prasad K. M. N., Wu T. Y., Ragunandam M. E. R., \& Raman R. N. (2014). Utilization of Plant-based Natural Coagulants as Future Alternatives Towards Sustainable Water Clarification. Journal of Environmental Science, 2178-2189.

Delelegn, A., Sahile, S., \& Husen, A. (2018). Water purification and antibacterial efficacy of Moringa oleifera Lam. Agriculture \& Food Security, 7(1), 25.

Eman, N. A., Suleyman A.M., Hamzah M.S., Zahangir A. and Mohd R.M.S. (2010). Production of Natural Coagulant from Moringa Oleifera Seed for Application in Treatment of Low Turbidity Water. J. Water Resource and Protection, 2,259-266.

Fleming C. A., Trevors J. T., (1989). Copper Toxicity and Chemistry in the Environment: A Review. Water, Air, and Soil Pollution Research, 44(1), 143-158.

Foster S. (2000). Efficient Wastewater Treatment: The Field for Analytical and Monitoring Equipment. Retrieved from http://www.ecoweb.com/edi/01759.html, 10th November 2017.

Gholamreza N. B., Totem S., \& Hariri. (2009). Plantago Ovata Efficiency in Elimination of Water Turbidity. Journal of Water Resource and Protection, 2, 90-98.

Jadhav V. M., Mahajan S. Y. (2013). A Comparative Study of Natural Coagulants in Flocculation of Clay Suspension of Varied Turbidity. International Journal of Civil and Environmental Engineering, 35(1), 1701-1782.

Kaggwa R. C., Mulalelo C. I., Denny P., \& Okurut T. O. (2001). The Impact of Alum Discharges on Natural Tropical Wetland in Uganda. Water Research, 35(3), 795-807. 
Mokhtar M. F., Abd Latib E. H., Sufian S., \& Ku Shaari K. Z. (2013). Preparation of Activated Carbon from Durian Shell and Seed. Advanced Materials Research, 626, 887-891.

Monica Nandini G. K., Chris M. (2016). Emanating Trends in The Usage of Biocoagulants in Potable Water Treatment: a Review. International Research Journal of Engineering and Technology, 3(11), 970973.

Muyibi S. A., Evison L. M. (1996). Moringa oleifera Seeds for Softening Hard Water. Water Reasearch, 6(3), 1109-1115.

Phyu M., Kyu H. (2017). Improvement of Water Quality in Flooded Area Using Plantbased Materials. International Journal of Scientific \& Engineering Research, 8(6), 1551-1552.
Saharudin N. F., (2014). Wastewater Treatment by using Natural Coagulant. Master thesis, Taylor's University, Malaysia.

Shan, T. C., Matar, M. Al, Makky, E. A., \& Ali, E. N. (2017). The use of Moringa oleifera seed as a natural coagulant for wastewater treatment and heavy metals removal. Applied Water Science, 7(3), 1369-1376.

Warhust A. M., McConnachie G. L., \& Pollard S. J. T. (1996). The Production of Activated Carbon for Water Treatment in Malawi from The Waste Seed Husks of Moringa oleifera. Water Science and Technology, 34(11), 177-184.

Zhou H., Smith D. W. (2002). Advanced Technologies in Water and Wastewater Treatment. Journal of Environmental Engineering and Science, 1(4), 247-264. 
